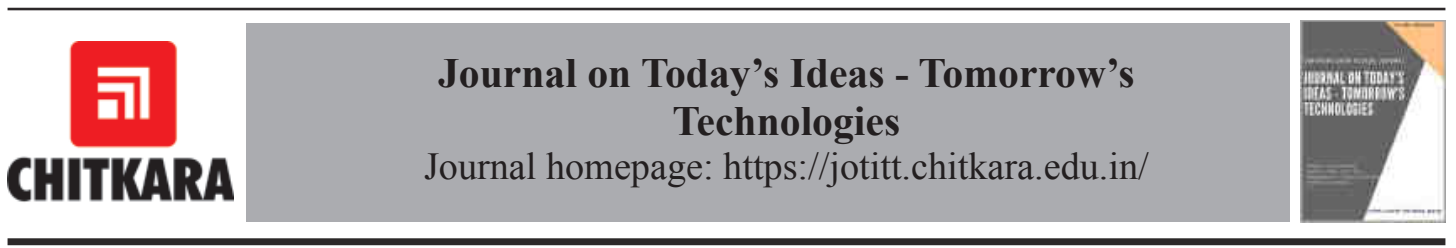

\title{
Skyscrapers: Origin, History, Evolution and Future
}

\author{
Pinak Ray ${ }^{1}$, Subham Roy ${ }^{2}$ \\ ${ }^{\prime}$ Jadavpur University, Kolkata, India. \\ ${ }^{2}$ University of Engineering and Management, Kolkata, India. \\ 1Email: pinak.ray@uem.edu.in
}

ARTICLE INFORMATION

DOI: $10.15415 /$ jotitt.2018.61001

Keywords: Earthquake, evacuation, safety elevator, green building, Kangaroo cranes

\begin{abstract}
From humble cottages to super tall structures, human beings have progressively developed the living and working space with time. This paper describes the origin and growth of modern skyscrapers, the subsequent challenges faced, and the way it was outdone. Research papers and case studies have been thoroughly studied and important excerpts from them have been explained to show how the modern structures have been evolved. The sources and causes of evolution is debatable among researchers, this paper has taken into account 7 most vital milestones in the growth of current generation skyscrapers and their contribution to the construction industry and concludes with the ideas and scopes where growth is still possible and challenges need to be solved.
\end{abstract}

\section{Introduction}

With the advent of $21^{\text {st }}$ century, the world has witnessed an overwhelming growth in the dynamics of building construction that was not thought of earlier. The very limits of the maximum height, width, nature and capacity of buildings have been stretched. Governments and private sectors with enough money and economy are constantly planning buildings that would be unique of its kind. Architects are being asked to design such marvelous escapades that would attract the attention of all humans. In turn the engineers involved are constantly facing challenges to bring such masterpieces to life. This unique construction boom has not only led to the creation of cities in the skies, it has compelled the engineers to keep updating their construction methodologies [1]. As the Jeddah Tower rises from the sands of the Arabian Desert and promises to be the tallest structure man has ever made, this paper discusses about the origin of skyscrapers, their evolution and the future.

\section{The key to modern skyscrapers}

The modern skyscrapers owe their present status to seven key inventions that has revolutionized skyscraper engineering over time. They are mobility material, heat, speed, wind, earthquake and evacuation. The modernization of skyscrapers 
has been discussed by analyzing these seven key factors supported by seven case studies where they were first applied. These seven landmark buildings are the historic giants of the skyscrapers world, at the heart of each one lies a major technological invention that allowed engineers to reach taller height.

\subsection{Key 1: Mobility}

The first breakthrough in the skyscraper world first happened in the $19^{\text {th }}$ century. By then the engineers were already looking up to utilize the parameter which is called height. The buildings of that time were utmost 3 to 4 stories tall and the only means to reach the upper floors was stairs. An average human being could think of no more than 4 floors because his physical limitations wouldn't allow to climb more by foot. The builders realized that in order to make buildings taller they have to find a way to make people climb higher. The solution to the problem was elevator. However the elevator of that time had a very fatal disadvantage, it was carried up by ropes and when the ropes broke nothing could stop it.

The solution to this problem came from a young mechanic in Vermont Mr. Elisha G. Otis. He invented a device that could instantly stop a falling elevator. In 1854 he demonstrated his invention at the world's fair in New York.
The device was a simple and very clever invention. The critical rope was secured by a powerful wagon spring mounted on top of the elevator. This spring was connected to a set of metal prongon either side of the elevator, they ran along guiderails with teeth's along the side of the elevator, when the rope broke, the spring relaxed and forced the prongs into the teeth, locking the elevator in place.

With the challenge solved, the world witnessed the formation of the first tall building in downtown New York; the Equitable Life Insurance Company Headquarter (1870) (Fig. 1). This was a building of great significance as it was the first office building with an elevator. It was 43 meters tall with 7 and half floors. Before this building was constructed the lower floors were the costliest and the most desirable, however this building revolutionized the economics of real estate. The people became more interested in upper floors which received light, air and was away from the noise of the traffic, thus the invention of elevator completely changed the idea of the urban landscape. This idea of high cost of higher floors is still applicable today which was invented during the infant years of skyscrapers.

The building is considered by some to be the world's first skyscraper and the elevators used were based on hydraulic principle.

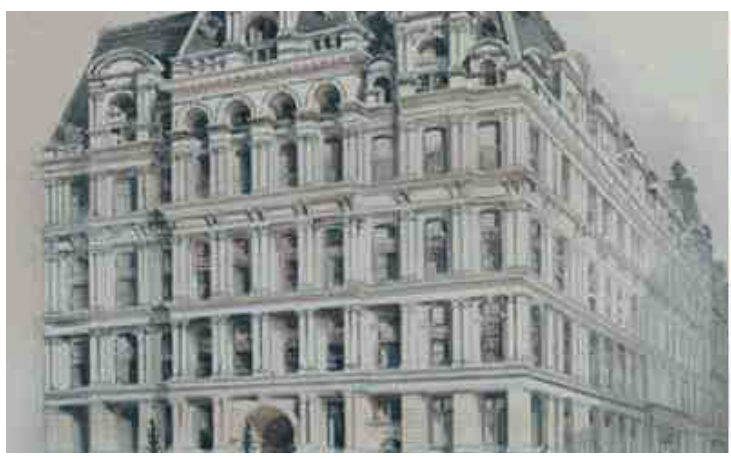

(a)

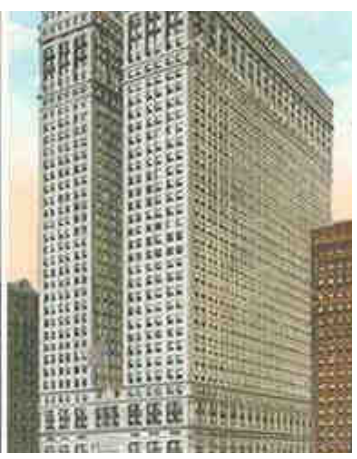

(b)

Figure 1: Equitable life insurance company headquarter (a) Old (b) New [image courtesy: us.axa.com]

ISSN No.: 232 1-3906 (Print) ISSN No.: 2321-7146 (Online) Registration No.: CHAENG/2013/51235 Periodicity: Bi-Annually 
Subsequent inventions followed that led to better elevators. Schuyler Wheeler invented the electric elevator and patented it in 1883. In 1874, J.W Meaker patented a method which permitted elevator doors to open and close safely. American inventor, Alexander Miles patented the elevator with automatic doors in 1887. In 2000 the first vacuum elevator was available commercially.

World's fastest elevator travels at a speed of $73.8 \mathrm{~km} / \mathrm{hr}$, was installed on July 7, 2016 in The Shanghai Tower.

Otis' invention would have remained an object of curiosity if some other trends didn't chance upon at the right time.

\subsection{Key 2: Materials}

The last decade of $19^{\text {th }}$ Century saw a huge demand for land. As economy rose, people wanted more private spaces for themselves which began to push the city outwards and led to high price of downtown lands of cities like New York and Chicago. This pressurized the real estate developers to provide more volume for the same amount of land. The only way to provide such service was to build taller buildings. The idea that a single foundation can be shared by multiple living spaces by utilizing the vertical space was already being looked upon as a lucrative option [2].

The safety elevator allowed the builders to go above 5 stories barrier, and made tall buildings a booming business. However the height was limited to 80 meters, beyond which the traditional building materials began to fail.

An incident alarmed the engineers of the impending danger of using traditional building materials to create taller building. It was 1893 when Monadnock building of Chicago (Fig. 2) began to sink into the ground under its own weight [3]. What happened was - when it was inaugurated in 1893, it became the world's largest office building. It had very thick walls of 2 meters thick to bear the weight of the 16 stories of Monadnock. The structure was so heavy that the bearing capacity of the soft Chicago soil under it failed and it began to sink. About half a meter of rock wall was disappeared into the ground and showed the engineers that rock were not a skyscraper material.

It was the architect of the Monadnock, Mr. Daniel Burnham who found the solution. He was asked to plan a tall building within a typical triangular land area. He fell in great dilemma while planning the Fuller Building in New York; the extremely narrow plot had to accommodate a 22 floored skyscraper.

Stone was not an option; they would have been so thick that the ground floor would not have any space left for use. To make his design viable Burnham decided to use steel. He made the skeleton of the building by interlocking steel beams and columns. Steel is stronger than stone which ensured that the skeleton $n$ would be light and thin and able to carry the whole load. Then as a finishing act he simply covered the whole building in thin masonry curtain which gave it a stone like look.

Steel constructions opened new horizons for the skyscraper world and the first building to use this technology was Fuller Flatiron Building (1902), height 87 meters (Fig. 2 and Fig. 3). 


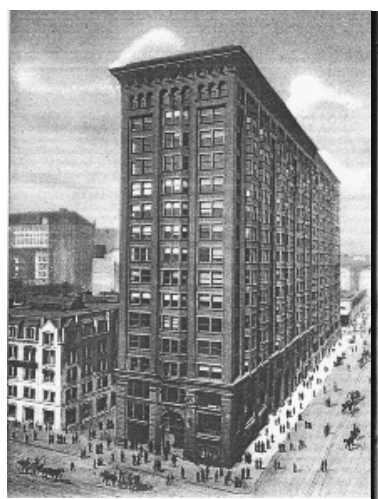

(a)

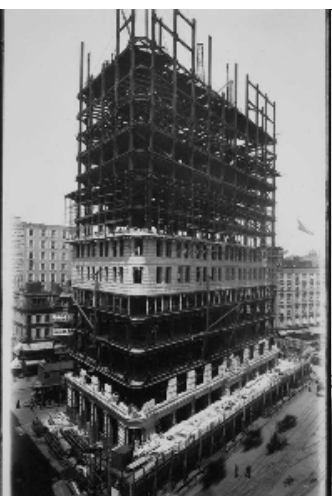

(b)

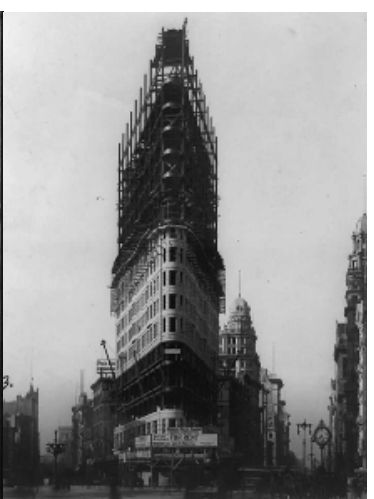

(c)

Figure 2: (a) Monadnock Chicago [image courtesy: pinterest.co.uk], (b) \& (c) Fuller Flatiron building [image courtesy: vintag.es.nycvintageimages]

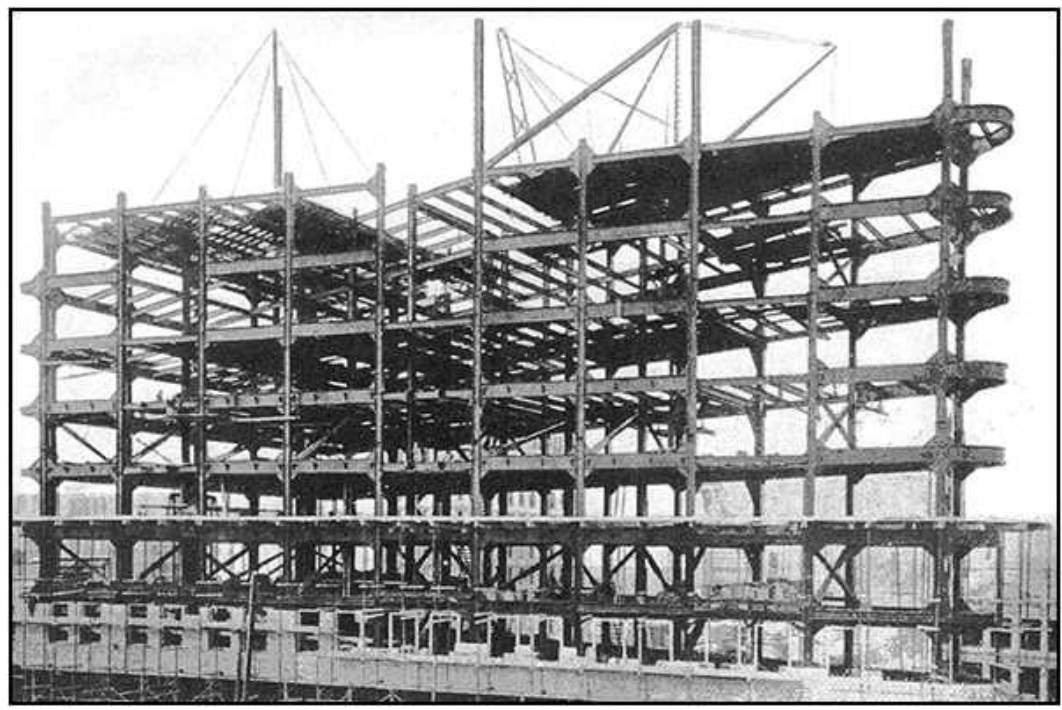

Figure 3: Fuller flatiron building skeleton construction [Image courtesy: nygeschichte.blogspot.

$$
\text { com] }
$$

In 1853, Francois Coignet a French industrialist had already introduced the capability of reinforced concrete by creating the first iron-reinforced concrete 4 storied building.

By the 1900s, the culmination of these four factors, high land price, the safety elevator and the introduction of steel and concrete as construction material started a national boom to construct tall buildings. This marks the beginning of the age of skyscrapers.

In 1913 for the first time Woolworth building reached 55 stories, with a height of 
241 meters.18 years later the Empire State Building reached 102 stories, height 381 meters.

In modern days reinforced concrete has been enhanced and new techniques like prestressed, poststressed concrete has been introduced, steel has been modified to provide better yield strength.

\subsection{Key 3: Heat}

As steel began to carry weight instead of walls, the height of the buildings began to soar high. Glass was used to let in light in these buildings, however it came with a problem: heat.

In 1947 the United Nations decided to design their 39 storied headquarters. They wanted it to be covered in glass to allow maximum light to enter and brighten the interiors. The idea was good yet had a great disadvantage; such a glass covered building would act as greenhouse. The glass wall would allow the heat radiation to enter which would in turn heat up the entire building, and the heat wouldn't escape. The only solution was artificial cooling [4].

An American Engineer Willis Carrier invented a machine that would cool hot moist air by making it wet. It used mist of cold water to absorb the hot soggy air which in turn cooled the air. This was the perfect solution to the heat problem. The air conditioning system not only allowed the buildings to rise higher, they could be built even in hot places anywhere in the world. Thus the United Nations Headquarters (168 meters) (Fig. 4) was built.

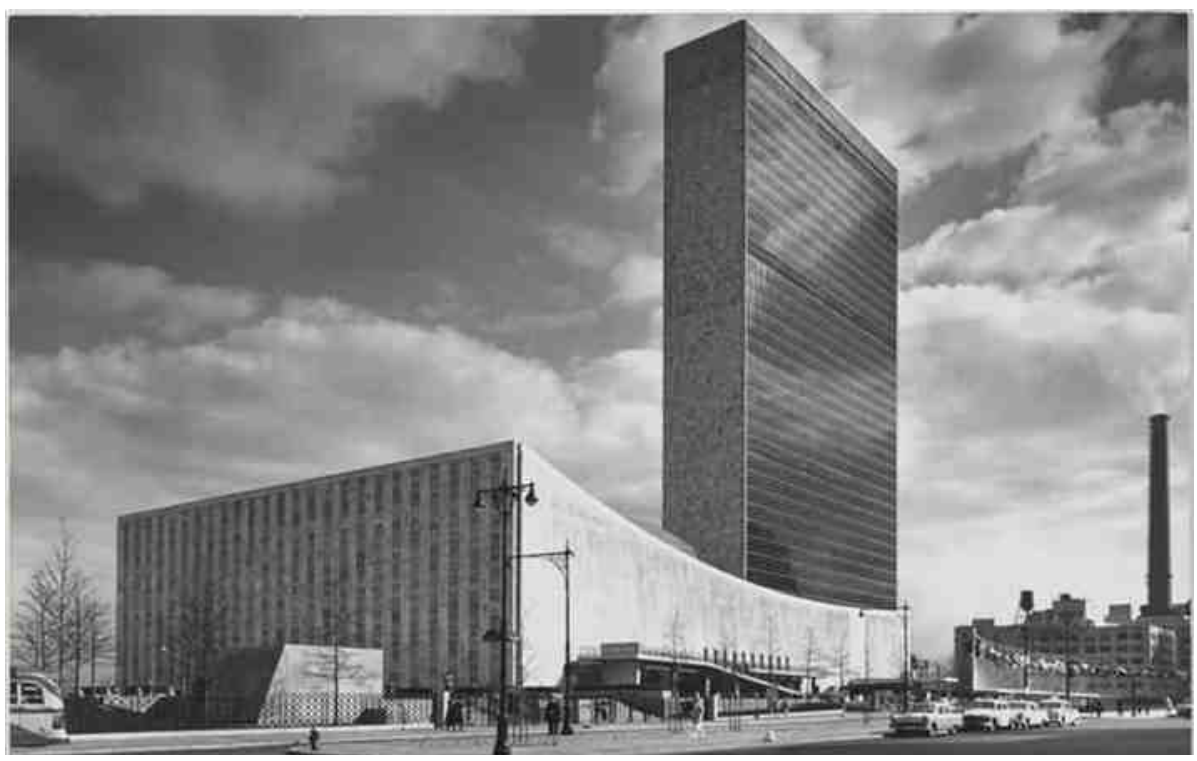

Figure 4: United nations headquarters (168 meters) with its glass facades [Image courtesy: ny.curbed.com]

From 1947 to 2017, glass as a construction material has improved dramatically. Glass and steel construction have become the face of development in many countries. In 1947 glass presented the problem of heating effect and paved the path for the invention of air conditioning system as a necessity of the time, however in 2010, the glass itself was 
used in advanced form in Burj Khalifa to filter the heat radiation and air conditioning became a luxury.

In Burj Khalifa the glass has an outer coating and inside coating. The outside coating reflects the solar radiation coming directly from the sun. The inside coating reflects the infrared radiation from the hot desert sand.

The world has moved from single air conditioning systems to central air conditioning system.

\subsection{Key 4: Speed}

As the buildings became more grand and high, the construction time began to increase. More time taken meant more money to be invested which became problem for the builders. Apart from that as the time to build increased it caused road blockages and harassment to the public. The builders had to find way to minimize the required time to absolute minimum. They found the solution by pre fabricating parts in workshops and installing them on site [5].

A great example of the use of this technology is the erstwhile Twin Towers of New York (Fig 6). The builders built pre fabricated parts of the tower and assembled them as giant jigsaw puzzle. Each piece consisted of three columns, three stories tall, connected by spandrel plates. The sections were fabricated away from the city and brought them to the site when needed [6]. They faced another problem, how to lift such heavy sections in less time? The team searched and found answer in Australia, a revolutionary crane that could lift upto 50 tones. The special feature of these cranes was they could shift up their base; hence they were called Kangaroo cranes (Fig 5).

Four such cranes were set up which could access all corners of the towers and after assembling 3 floors they jumped up higher. With the help of the pre-fabricated sections and Kangaroo Cranes the Twin Towers were built at a whooping speed of 2 floors per week. It was completed in 1970 and became the tallest building in the world with a height of 417 meters.

Kangaroo cranes are still used for high rise building. However the basis of increasing speed has shifted from cranes to formwork. In current scenario the way of shuttering is one of the prime factors to reduce the construction time on site. One of these is Slip Form Shuttering which can be moved by means of hydraulic jacks from lower to upper floors. Metal formwork has replaced wood form work for internal shuttering.

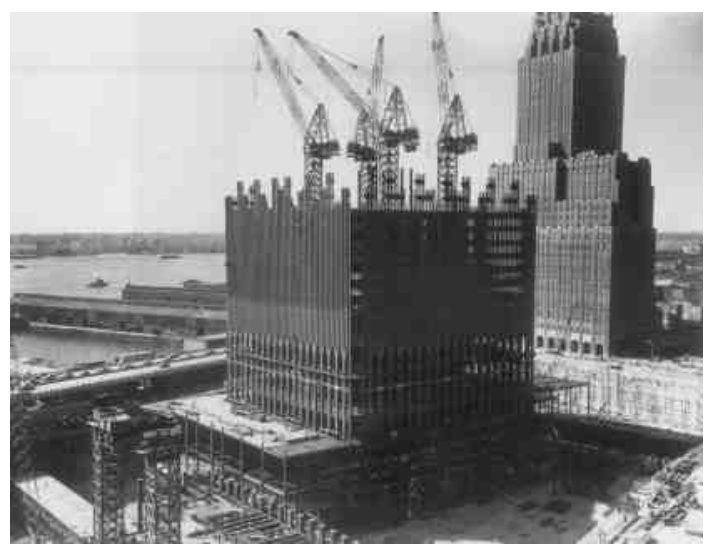

Figure 5: Construction of erstwhile world trade center using four Kangaroo cranes [Image courtesy: raredelights.com ] 


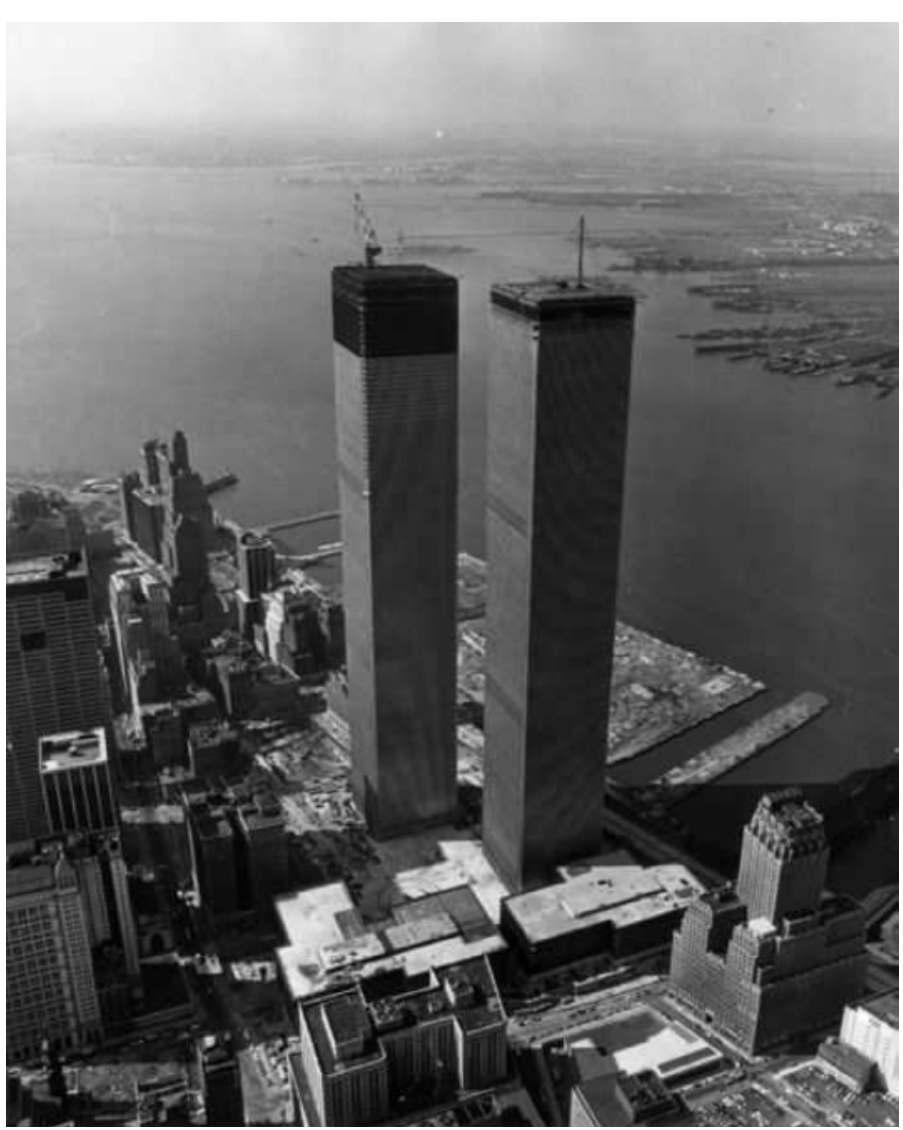

Figure 6: Erstwhile world trade center nearing completion [Image courtesy: fineartstorehouse. com]

\subsection{Key 5: Wind}

Tall and slim building slowly became a prominent solution to accommodate increasing density of population in major cities. However as the materials became light the buildings became prone to vibrations, which becomes both discomforting to the users as well as cause structural failure.

These tall buildings need to withstand various external forces such as earthquakes and strong winds [7]. Thus motion control of buildings was given due consideration taking into account both static and dynamic loads. Two solutions were thought of, first to increase the structural stiffness and second to damp the external vibrations while keeping the material quantity minimum.

As the buildings became taller they got exposed to a formidable enemy that exploited all of their weaknesses. In 1970 while the architects designed the 442 meters tall Sears tower in Chicago (Fig. 7) they faced a great challenge. The windy city ensured a huge wind load on the 100 stories tall planned tower.

Traditional steel skeletons failed at this height as such wind force would cause them to 
bend and sway. Such movements would cause sea sickness like physical problems and dread among the people. The architects of the Sears Towers invented the technology to beat the wind. They shifted the internal skeletal frame and merged them with the external frame which formed an exoskeleton. This framework was very hard for the wind to bend [8].

The Sears Tower was built by interlocking such 9 exoskeletons which made it wind proof. Thus the concept of exoskeleton was invented which is still the best way to minimize wind sway.

Besides the problem of bend and sway, the shape of the building also plays a critical factor in determining the impact of the wind load on the structure. As the path of the wind is obstructed by a building it goes around and flows again in its normal path creating suction in the leeward direction. Thus the total wind load becomes the summation of windward pressure and leeward suction.

Present day modification includes testing of prototypes in wind tunnels, and use of aero dynamic designs (Fig. 8) to reduce this suction effect of wind.

Another development that went on parallel was the research on dampers and there probable use in infrastructure. Damping systems were initially used by the mechanical industry and experimentation with damping in construction industry started in 1950s.

The first application of damping system in tall buildings was in 1969 with the erstwhile World Trade Centre, New York. Then the use of damping systems increased extensively in 1980 s as part of retrofits in old buildings.

Currently available damping systems can be divided into two broad categories: passive system and active system. Passive system is recognized by fixed properties while the property of active systems change based on the load demand, and is activated by an external source of energy.

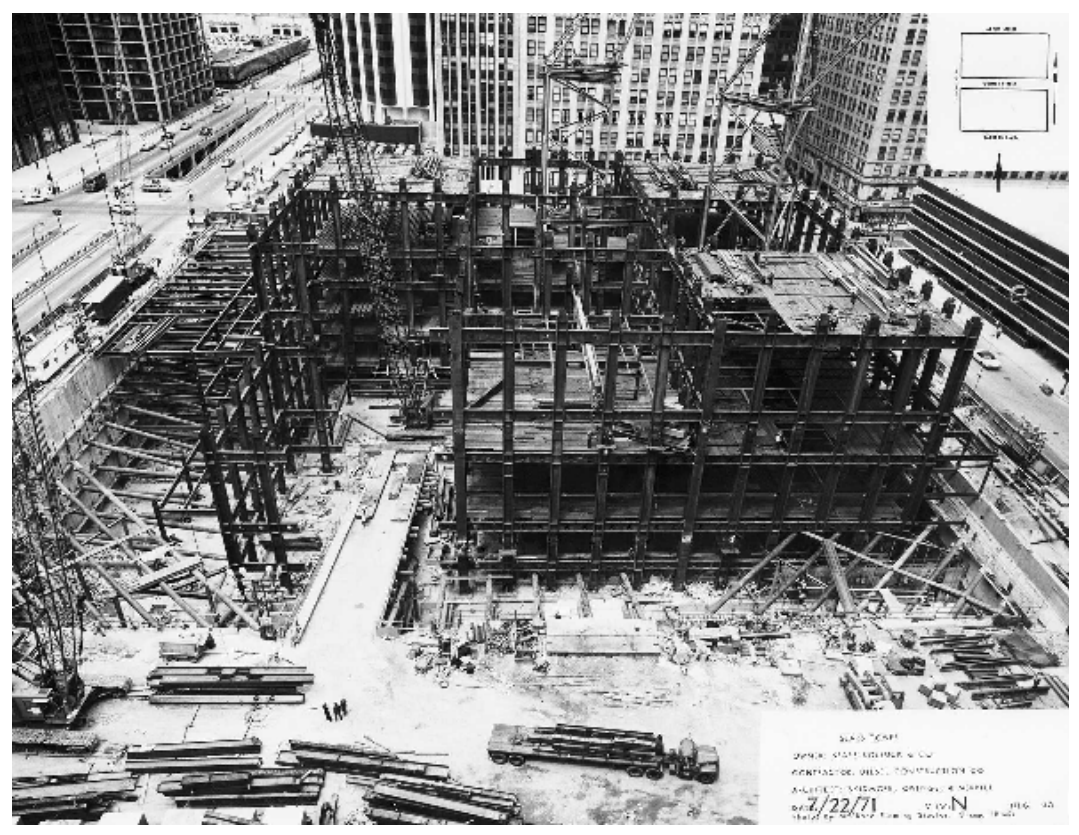

Figure 7: Sears tower exoskeleton [Image courtesy: som.com] 


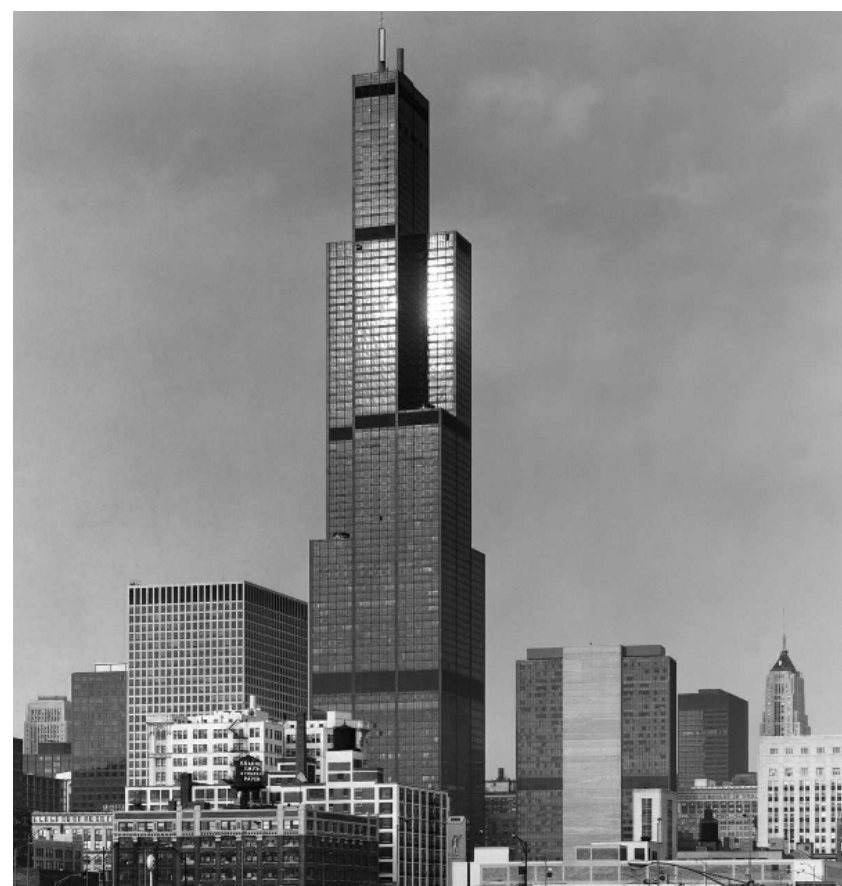

Figure 8: Completed sears tower with its aerodynamic design [Image courtesy: som.com]

\subsection{Key 6: Earthquake}

With such developments in the tall structures, Asian countries began to desire them. However Asia experienced a natural disaster that European skyscrapers didn't face before - Earthquakes.

With the knowledge of earthquake and their impact on buildings, earthquake resistant structures were designed which depended on wind bracings. Tests and calculations showed that they were able to resist the jerking effect of earthquakes.

In 1999, the architects were designing Taipei 101 in Taiwan (Fig. 9) faced the problem of earthquakes. Taiwan is located near the Pacific Ring of Fire and experiences an average of 2 earthquakes every year. They had to find way to prevent the earthquake waves from shaking the building. Engineers found out that the building had to be elastic enough to absorb the energy from the earthquakes.

The engineers of Taipei 101 planned an ingenious way to create an earthquake proof structure [9]. The whole building was made around 36 rigid steel tube columns filled with concrete to provided strength. The rest of the structures were made elastic such that they would flex and move with the waves. Halfway during construction the building was hit by an earthquake and the design proved to be true to its needs. It is built to withstand the typhoon winds and earthquake tremors common to the region. The unique design makes the building both flexible to prevent structural damage and structurally resistant which ensures comfort for the occupants.

The Taipei 101 was finally completed in 2004 and has a height of 509 meters.

Earthquake engineering is one of the most significant research areas that the scientists are 
working on. No building can be made earthquake materials and foundations that can absorb shocks proof however we can reduce its effect by using from seismic waves [10].

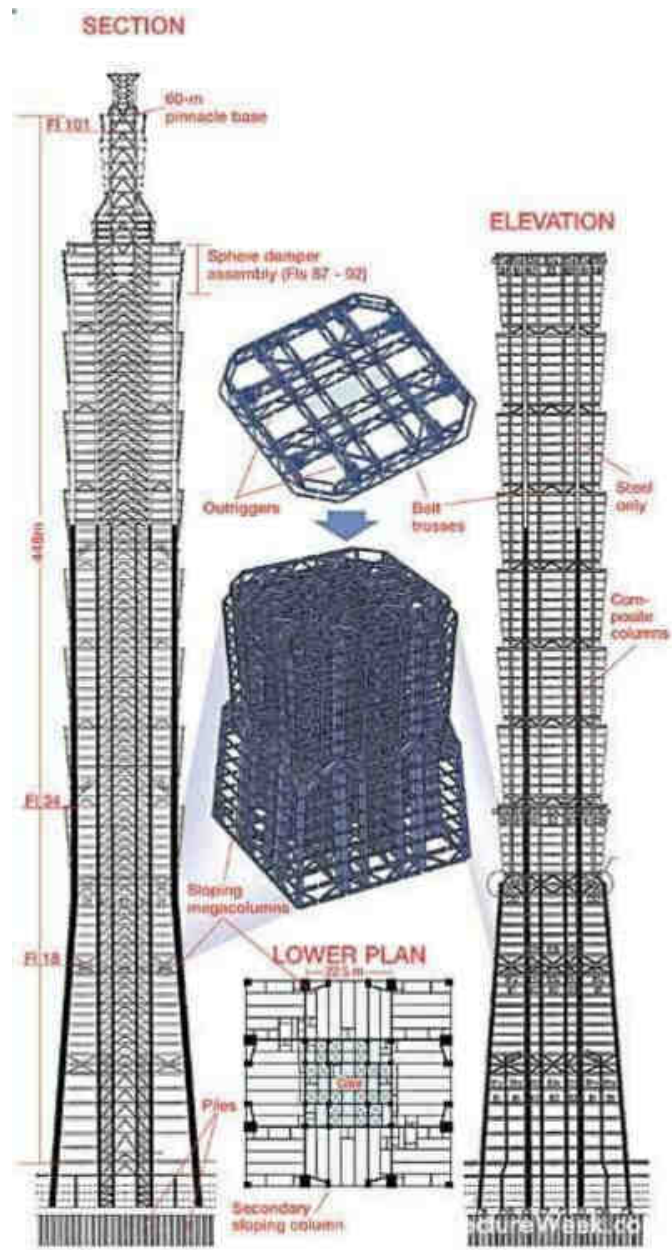

Figure 9: Frame of taipei 101 with its interlocked steel tubes [Image courtesy: pinterest.co.uk]

\subsection{Key 7: Evacuation}

As the building rose higher it became increasingly difficult to evacuate the residents during disasters. People are not allowed to use elevators during fire or other such emergencies. As the buildings shelter huge number of people, in case of emergencies the rush might cause further casualties. The final problem faced by the engineers was evacuation.
After the attacks of $9 / 11$, it was high time for the engineers to find a solution. Burj Dubai's design uses one of the prominent solutions; it has built in fire protection. Evacuating huge number of people takes long time and involves a huge risk, so architects of Burj, Dubai decided to create fail safe within the building the itself. The building has 9 very special 
refuge rooms made from reinforced concrete layers and fire proof sheeting; these rooms withstand fire for 2 hours. They have special supply of air from fire resistant pipes and sealed fire proof doors to prevent smoke. There's 1 room in every 30 floors to shelter people in terms of need until emergency services come for rescue.

In order to prevent smoke from blocking the vision, a set of high powered fans are fitted on the stairways. In case of fire they get triggered and force in fresh air through ducts into the building. The air pushes the smoke away from the stairs and keeps it clear.

Completed in 2008 BurjKhalifa currently holds the record of being world's tallest building with a height of 828 meters.

\section{Future of skyscrapers}

As architects continue to design skyscrapers, the goals has changed, height is not the most important thing at present. Designing the skyscraper of the future is about making its space more efficient than ever. The sought after things include: added comfort, green building for better energy conservation, more control for building tenants etc. The real limit to skyscraper technology still remains to be the limits of the elevator. The steel cords can hold only so much weight before the load becomes too heavy to carry.

Energy efficiency is one of the prime driving forces behind designing skyscraper of the future. Today energy efficiency determines the economic value of the building not height. One of main ways to do so is harnessing energy from renewable energy sources such as solar energy, or saving resources such as water from rain.

Skyscrapers of the future will not only grow upward, they will integrate themselves with smart technology and become multifunctional.

Current tall structure researches involve these 11 fields: [11].

1. Urban Design, City Planning and Social Issues.

2. Architecture and interior design.

3. Economics and Cost.

4. Structural Performance, Multi-Hazard Design and Geotechnics.

5. Circulation: Vertical Transportation and Evacuation.

6. Fire and Life Safety.

7. Cladding and Skin.

8. Building materials and Products.

9. Sustainable Design, Construction and Operation.

10. Construction and Project Management.

11. Energy: Performance, Metrics and Generation.

The Jeddah Tower when completed will be the world's tallest tower with height of $1000 m$ vertically.

\section{Conclusion}

In 2018 , the world population is 7.2 billion and is projected to be 9.6 billion by 2050 , which can only be properly sheltered by adequately utilizing land. In order to provide shelter to such huge population it is essential for the engineers to keep on building more innovative mega tall skyscrapers.

\section{References}

[1] Criteria for the Defining And Measuring of Tall Buildings, CTBUH, Chicago, I, 2014.

[2] D. Friedman, Historical Building Construction: Design, Materials, and Technology, $2^{\text {nd }}$ Edition. New York: W. W. Norton \& Company, 2010. 
[3] T. Leslie, "The Monadnock building, technically reconsidered", $C T$ BUH Journal, no. 4, pp. 26-31, 2013.

[4] J. J. Tomlinson, Heat Recovery from Wastewater Using a GravityFilm Heat Exchanger, Rev. Federal Energy Management Program, Oak Ridge National Laboratory, 2001. [Online] Available: https:/ / catalogue.nla.gov.au/ Record/4471856.

[5] S. Giedion, "Space, Time, and Architecture: The Growth of a New Tradition" ( $5^{\text {th }}$ Edition). Cambridge: Harvard University Press: 382, 1997.

[6] J. Klerks, "Planning the world trade center: 40 Years Apart”, CTBUH Journal, no. 3, pp. 26-29, 2011.

[7] H. H. Quimby, Wind Bracing in High Buildings, The Engineering Record, November, pp. 394-395, 1892.

[8] The Wind Bracing of Buildings, CONDIT,C. Scientific American, vol. 230, no. 2, 98,1974.

[9] D. Poon, et al. "Structural design of taipei 101, the world's tallest building", CTBUH 2004, October 10-13, Seoul, Korea, 2004, pp, 271278.

[10] D. N. M. Lee, "Application of tuned liquid dampers for the efficient structural design of slender tall buildings", CTBUH Journal Issue, vol. 4, pp. 30-36, 2010.

[11] P. Oldfield, D. Trabuccoand A. Wood, "Roadmap on the Future Research Needs of Tall Buildings”, Council on Tall Buildings and Urban Habitat: Chicago, 2014. 